\title{
Decrease in health-related quality of life associated with awareness of hepatitis $C$ virus infection among people who inject drugs in Scotland
}

\author{
Scott A. McDonald ${ }^{1,2, *}$, Sharon J. Hutchinson ${ }^{1,2}$, Norah E. Palmateer ${ }^{1}$, Elizabeth Allen ${ }^{3}$, \\ Sheila O. Cameron ${ }^{4}$, David J. Goldberg ${ }^{1}$, Avril Taylor ${ }^{3}$ \\ ${ }^{1}$ Health Protection Scotland, Meridian Court, 5 Cadogan Street, Glasgow G2 6QE, Scotland, UK; ${ }^{2}$ Department of Mathematics and \\ Statistics, University of Strathclyde, 26 Richmond Street, Glasgow G1 1XH, Scotland, UK; ${ }^{3}$ University of the West of Scotland, Paisley PA1 \\ 2BE, Scotland, UK; ${ }^{4}$ West of Scotland Specialist Virology Centre, Gartnavel General Hospital, Glasgow, UK
}

Background \& Aims: Chronic hepatitis C virus (HCV) infection can significantly reduce health-related quality of life (QoL), but it is not clear if reduction is associated with the infection or with being aware of one's infection status. Understanding the impact of a HCV diagnosis on $\mathrm{QoL}$ is essential to inform decision-making regarding screening/testing and treatment.

Methods: Using a cross-sectional design, we assessed QoL in 2898 people who inject drugs (PWID), surveyed in Scotland during 2010 using EQ-5D. Multifactorial regression compared self-reported QoL between PWID who were (i) chronically HCV-infected and aware of their infected status, (ii) chronically HCV-infected but unaware, and (iii) not chronically infected.

Results: Median time since onset of injecting was 10 years; not chronically infected PWID were younger and had shorter injecting careers than chronically infected PWID. Median EQ-5D was highest for the not chronically infected and the chronic/unaware groups (0.73) compared with the chronic/aware group (0.66). After adjustment for demographic and behavioural co-factors, QoL was significantly reduced in chronic/aware compared with chronic/unaware PWID (adjusted $B=-0.09, p=0.005$ ); there was no evidence for a difference in QoL between not chronically infected and chronic/unaware PWID (adjusted $B=-0.03$, $p=0.13$ )

Conclusions: Awareness of one's chronic HCV status was associated with reduced health-related QoL, but there was no evidence for further reduction attributable to chronic infection itself after adjusting for important covariate differences.

(c) 2012 European Association for the Study of the Liver. Published by Elsevier B.V. All rights reserved.

Keywords: Quality of life; HCV; EQ-5D; People who inject drugs.

Received 22 August 2012; received in revised form 10 October 2012; accepted 5 November 2012

* Corresponding author. Address: Health Protection Scotland, Meridian Court, 5 Cadogan Street, Glasgow G2 6QE, Scotland, UK. Tel.: +44 141300 1106; fax: +44 1413001170

E-mail address: smcdonald4@nhs.net (S.A. McDonald).

Abbreviations: QoL, quality of life; HCV, hepatitis C virus; PWID, people who inject drugs; NESI, Needle Exchange Surveillance Initiative; HB, health board; DBS, dried blood spots; GGC, Greater Glasgow \& Clyde.

\section{Introduction}

More than 50,000 people are estimated to be infected with the hepatitis C virus (HCV) in Scotland, of whom 90\% are current/former people who inject drugs (PWID) [1]. The risk of progression to severe liver disease in this population is many times that of the general population [2-4]. Although previous research has shown that PWID have lower QoL in comparison with reference populations [4], and chronic HCV infection can significantly reduce health-related quality of life (QoL) in PWID and clinical cohorts [5,6], there is little evidence regarding the association between QoL and awareness of one's infection status in HCV-infected PWID [4,7].

For estimation of the cost-effectiveness (CE) of HCV antiviral therapy, models have used data on patients' QoL pre- and posttreatment; for those in the pre-treatment stage, QoL is inferred from patients who have already been diagnosed and are aware of their chronic HCV infection status [8]. CE studies use simulation methods to project improvements in QoL post-treatment, and baseline QoL assumptions are often derived from earlier studies [8-9]. For estimation of the CE of HCV testing/screening programmes [10], data are required documenting the change in utility from untested to tested status, so that effects on QoL attributable to the receipt of a positive diagnosis in both patients selected and not selected for treatment can be incorporated in the modelling.

To better understand the relationship between HCV infection, awareness of one's infected status, and perceived health-related QoL, the current study compared QoL using EQ-5D (a standardised measure of health status) in three subgroups consisting of infected/aware, infected/unaware, and not chronic PWID in a sample of approximately 3000 injectors, attending services providing injecting equipment in Scotland.

\section{Materials and methods}

Data source

The Needle Exchange Surveillance Initiative (NESI) is an ongoing project that aims at measuring and monitoring the prevalence of HCV infection and injecting risk 


\section{Research Article}

behaviours among PWID in Scotland. Starting in 2008/2009, a cross-sectional voluntary anonymous survey has been conducted to collect demographic, lifestyle and substance abuse data from PWID in 11 mainland Scottish health boards (HBs) [11]. Participants were recruited by trained interviewers, from selected services and pharmacies that provide injecting equipment, from January to November 2010. Services/pharmacies were selected to be broadly geographically representative and to meet logistical constraints, namely availability of a room where participants could be interviewed in private. Participants were recruited from 109 pharmacies and 26 agencies (with 39 separate sites) providing a fixed site exchange, mobile or outreach service across the 11 mainland HBs; this represents more than half of all services providing injecting equipment in Scotland [12]. People attending recruitment sites for other harm reduction services (e.g., methadone prescription) are also invited to participate.

Participants were eligible if they had ever injected drugs and had not taken part in the current survey; non-active PWID (those who had not injected in the past 6 months) were kept to a maximum of $25 \%$ in the sample. Dried blood spot (DBS) samples are solicited and are tested anonymously for HCV antibody and RNA, and test results were linked to the questionnaire data via a common study number. Ethical approval for NESI was received from the West of Scotland Research Ethics Service.

In the second sweep of the survey in 2010, the NESI questionnaire was expanded to include the five-component EQ-5D [13,14], a standardised, generic instrument for measuring QoL designed for self-completion; EQ-5D is acknowledged as the most appropriate utility measure for this population [15]. The EQ$5 \mathrm{D}$ questionnaire was administered face-to-face by a trained interviewer. The five dimensions measured are: mobility, self-care, usual activities, pain/discomfort and anxiety/depression. Each dimension has three response levels indicating severity (no problems; some problems; severe problems). To derive a single summary index QoL value from the five-dimensional EQ-5D response state, valuations derived from a UK general population sample (2997 respondents, 1993) were applied using an established algorithm [16]. A maximum score of 1 indicates the best possible health state.

DBS were supplied by $99.9 \%$ of 3100 respondents, and were tested for HCV antibody and HCV RNA at the West of Scotland Specialist Virology Centre. Testing used a modified protocol for the Ortho SAVe 2.0 ELISA (Ortho Diagnostics, Amersham, with a reported sensitivity and specificity of $99 \%$ and $100 \%$, respectively [17]). Reactive samples were repeated using the same assay and a small number of weakly reactive samples were tested further using modified protocols of the recombinant immunoblot assay (RIBA). RNA was extracted from DBS using the bioMerieux (Lyon, France) extraction protocol and a real-time PCR assay was undertaken. Testing was initially carried out in pools of five then positive pools were tested individually. After excluding participants who declined to supply a DBS specimen $(\mathrm{n}=2)$, or whose provided sample was inadequate for testing $(n=73)$, or for whom HCV and/or RNA status could not be determined $(n=95)$, or who had incomplete age or sex information $(n=8)$, or did not complete EQ-5D $(n=28)$, the study population consisted of 2898 ever-PWID.

Outcome and other variable definitions

The outcome variable was the EQ-5D summary index. The main determinant of interest, HCV chronically infected status (chronic HCV/aware, chronic HCV/ unaware, not chronic HCV), was defined according to HCV antibody and PCR test results and the participant's response to the question 'Would you mind telling me the result of your last [hepatitis C] test?'. Possible answers included 'Have hep C', 'Cleared hep C', and 'Did not have hep C'. Specifically, the status 'chronic HCV/aware' was assigned to individuals who tested (anonymously) HCV antibody-positive and RNA-positive and who self-reported as 'Have hep C'. 'Chronic HCV/unaware' relates to persons who tested HCV antibody-positive and RNA-positive and self-reported as one of 'Did not have hep C', 'Cleared hep C', 'Awaiting result', 'Did not get result', 'Do not want to say', 'Don't know', 'Not tested', or whose response was recorded as missing. 'Not chronic HCV' consisted of all individuals who tested HCV RNA-negative. A small number of cases who tested HCV antibody-negative/RNA-positive were excluded from analysis.

Other data recorded in the NESI questionnaire included as covariates were age, sex, injecting frequency in the previous 6 months (coded as non-active, less than once per day, or $\geqslant 1$ times/day), ever on methadone (never, currently, or in past), ever in prison, and ever homeless (never, in past 6 months, or $>6$ months ago). Reported alcohol consumption in the previous 12 months was coded as non-drinker, moderate ( $>0$ to 21 units/week for males; $>0$ to 14 units/week for females), or high (>21 units/week males, $>14$ units/week females). Health board of residence was divided into two categories: Greater Glasgow \& Clyde (GGC), and all other HBs.
Data analysis

EQ-5D index values were compared to published data from a UK reference population ( $\mathrm{n}=3395$, 46\% male, minimum age 18 years) for which QoL was valuated using EQ-5D [18]; reference population mean QoL values and standard deviations were weighted according to the sex and 10-year age group distribution of our study population. Differences in EQ-5D index value between the study and reference populations were assessed using the two-sample $t$-test.

For comparison of demographic characteristics and behavioural data between the three HCV status groups, the Kruskal-Wallis test was applied in the case of continuous variables, and the $\chi^{2}$ test was applied for dichotomous/categorical variables.

Because the distribution of EQ-5D values was highly skewed, linear regression was deemed inappropriate and median (quantile) regression analysis was used instead to estimate the association between EQ-5D index and HCV status, adjusting for the aforementioned covariates. Tests of interactions between HCV status and each of sex, alcohol use, and injecting frequency were planned a priori and fitted separately, and retention of interaction(s) in the final model was determined if inclusion significantly improved model fit, according to Akaike's Information Criterion. All statistical analyses were conducted using $\mathrm{R}$ statistical software [19].

Due to certain discrepancies between reported HCV status and actual RNA status, (i) PWID who had tested HCV RNA-positive but had reported 'Don't have hep C' or 'Cleared hep C', and (ii) PWID who had tested HCV RNA-negative but had responded 'Have hep C', sensitivity analyses were undertaken in which each of these groups was excluded from the total study population.

\section{Results}

\section{Demographic characteristics}

Characteristics of the study population according to HCV status are provided in Table 1. Overall, 67\% (1941/2898) of respondents were deemed recent PWID (injected within the previous 4 weeks). The median time since onset of injecting was 10 years; $11 \%$ had their injection debut within the previous two years. Eighty-four percent of respondents indicated heroin to be the only drug injected. The majority $(90 \%)$ of respondents reported having ever been on methadone (77\% currently and $13 \%$ in the past). PWID not chronically infected with HCV represented $62 \%$ (1806/2898) of the sample, followed by chronic HCV/aware (20\%) and chronic HCV/unaware (18\%). The not chronic HCV group was younger on average and had shorter injecting careers than either chronic HCV/aware or chronic HCV/unaware PWID $(P s<0.001$ ), and reported alcohol intake (summing moderate and high intake categories) was greatest for the chronic HCV/unaware group.

\section{Quality of life measures}

The distribution of responses over each EQ-5D dimension is shown in Fig. 1. The largest proportion of 'severe' responses was observed for the dimensions anxiety/depression and pain/ discomfort. Mean EQ-5D index was significantly lower in comparison with UK population norms $(t=-46.9)$, after standardisation for the sex and age composition of our study population.

Table 2 displays the distribution of respondents according to HCV test result and perceived HCV status, with unadjusted median EQ-5D for each cell of the table. A higher proportion (84\%) of HCV RNA-positive participants (from anonymous testing) reported having been tested for HCV in the past compared with those $(75 \%)$ who were HCV RNA-negative; $p<0.0001$. However, among those HCV RNA-positive who reported having ever been tested, 21\% (193/913) said that they did not have HCV (possible 
Table 1. Characteristics of the study population $(\mathrm{n}=\mathbf{2 8 9 8}$ ), according to HCV status.

\begin{tabular}{|c|c|c|c|c|c|}
\hline & Study population & $\begin{array}{l}\text { Chronic HCV and } \\
\text { aware }(\mathrm{col} \%)\end{array}$ & $\begin{array}{l}\text { Chronic } \mathrm{HCV} \text { and } \\
\text { unaware }(\mathrm{col} \%)\end{array}$ & $\begin{array}{l}\text { Not chronic HCV } \\
\text { (col\%) }\end{array}$ & $p$ value \\
\hline $\mathrm{N}(\%$ of $\mathrm{N})$ & $2898(100 \%)$ & $584(20 \%)$ & $508(18 \%)$ & $1806(62 \%)$ & \\
\hline Male & $2091(72.2)$ & $439(75.2)$ & $379(74.6)$ & $1273(70.5)$ & 0.04 \\
\hline Age at interview in years, Median [IQR] & 34 [29-39] & 37 [31-42] & $34[30-40]$ & 33 [29-38] & $<0.01$ \\
\hline Injecting career length in years, Median [IQR] & $10.2[5.3-15.5]$ & $13.5[9.4-20.1]$ & $11.2[7.0-15.8]$ & $8.5[3.8-13.7]$ & $<0.01$ \\
\hline Recent injector (injected in last $4 \mathrm{wk}$ ) & $1941(67.0)$ & $381(65.2)$ & $343(67.5)$ & $1217(67.4)$ & 0.61 \\
\hline \multicolumn{6}{|c|}{ Injecting frequency (in previous $6 \mathrm{mo}$ ), if had injected in last $4 \mathrm{wk}$} \\
\hline$<1$ occasion/d & $872(45.1)$ & $172(39.1)$ & $134(46.5)$ & $566(44.9)$ & \\
\hline$\geq 1$ occasion/d & $1069(54.9)$ & $209(60.1)$ & $209(53.5)$ & $651(55.1)$ & 0.05 \\
\hline \multicolumn{6}{|l|}{ Alcohol use (in previous $12 \mathrm{mo}$ ) } \\
\hline Non-drinker & $1516(52.3)$ & $310(53.1)$ & $225(44.3)$ & $981(54.3)$ & \\
\hline Moderate & $678(23.4)$ & $96(16.4)$ & $127(25.0)$ & $455(25.2)$ & $<0.01$ \\
\hline High & $704(24.3)$ & $178(30.5)$ & $156(30.7)$ & $370(20.5)$ & $<0.01$ \\
\hline \multicolumn{6}{|l|}{ Ever on methadone } \\
\hline Never & $277(9.6)$ & $25(4.3)$ & $37(7.3)$ & $215(11.9)$ & \\
\hline Currently & $2244(77.4)$ & $481(82.4)$ & $391(77.0)$ & $1372(76.0)$ & $<0.01$ \\
\hline In past & $377(13.0)$ & $78(13.4)$ & $80(15.7)$ & $219(12.1)$ & 0.21 \\
\hline \multicolumn{6}{|l|}{ Ever homeless } \\
\hline Never & $867(30.0)$ & $150(25.7)$ & $127(25.1)$ & $590(32.7)$ & \\
\hline Yes, $>6$ mo ago & $1386(47.9)$ & $300(51.4)$ & $346(48.5)$ & $840(46.6)$ & $<0.01$ \\
\hline In last 6 mo & $641(22.1)$ & $134(22.9)$ & $134(26.4)$ & $373(20.7)$ & $<0.01$ \\
\hline \multicolumn{6}{|l|}{ Ever in prison } \\
\hline Never & $1114(38.5)$ & $137(23.5)$ & $147(28.9)$ & $830(46.0)$ & \\
\hline Yes & $1783(61.5)$ & 447 (76.5) & $361(71.1)$ & $975(54.0)$ & $<0.01$ \\
\hline \multicolumn{6}{|l|}{ Health Board of residence } \\
\hline Greater Glasgow & $1318(45.5)$ & $309(52.9)$ & $288(56.7)$ & $721(39.9)$ & \\
\hline Other & $1580(54.5)$ & $275(47.1)$ & $220(43.3)$ & $1085(60.1)$ & $<0.001$ \\
\hline \multicolumn{6}{|l|}{ Drug(s) injected within last 6 mo } \\
\hline Heroin only & $1892(83.5)$ & $348(80.2)$ & $348(85.9)$ & $1196(83.9)$ & \\
\hline Stimulants ( \pm other drugs) & $300(13.2)$ & $78(18.0)$ & $53(13.1)$ & $169(11.9)$ & $<0.001$ \\
\hline Other & $73(3.2)$ & $8(1.8)$ & $4(1.0)$ & $61(4.3)$ & $<0.001$ \\
\hline
\end{tabular}

$\mathrm{IQR}$, interquartile range; d, day(s); wk, week(s); mo, month(s).

Self-rated alcohol use categories were defined as: high ( $>21$ units/week for males; $>14$ for females); moderate ( $>0$ to 21 units/week for males and $>0$ to 14 units/wk for females); non-drinker (0 units/week).

The Stimulants category consists of cocaine, crack, or amphetamines, with/without other reported drugs injected.

$p$-Values were determined according to either $\chi^{2}$ or Kruskal-Wallis tests, for frequencies and real-valued variables, respectively.

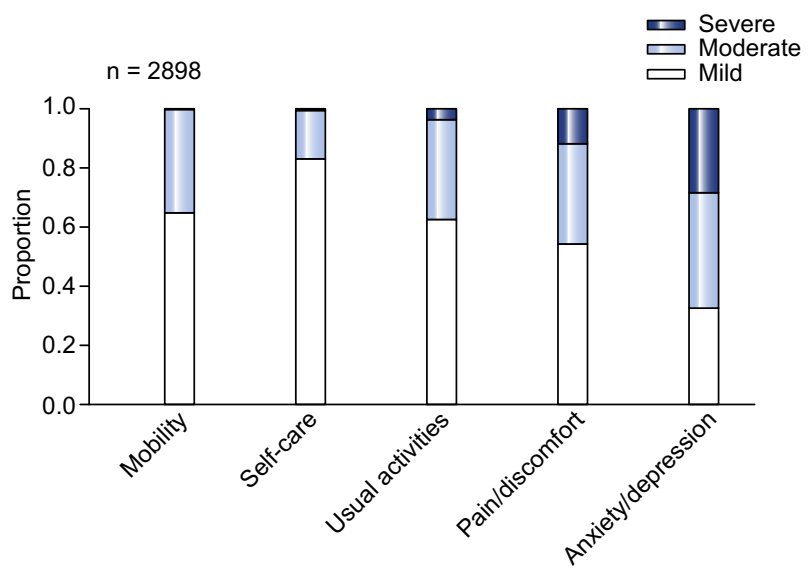

Fig. 1. Distribution of responses among the study population, for each of the five EQ-5D dimensions $(n=2898)$. if they had been tested for HCV prior to acquiring, or developing, chronic infection) and 5.5\% (49/913) reported that they had cleared HCV.

Fig. 2 compares crude outcome values for the three HCV status groups. Median EQ-5D index value was highest for the not chronic HCV (0.73, IQR: $0.35-0.84)$ and chronic/unaware $(0.73$, IQR: $0.31-1.0)$ groups, compared with the chronic/aware group (0.66, IQR: 0.21-0.85).

Multifactorial analyses

Results of multifactorial quantile regression analysis (considering the median as the relevant measure of central tendency) indicated that adjusting for covariates, chronic $\mathrm{HCV} / \mathrm{aware}$ individuals had a significantly lower QoL than chronic HCV/unaware (median values of 0.66 and 0.73 , respectively; regression coefficient $=-0.09, p=0.005)$, and that there was no significant difference between the not chronically infected and chronic HCV/ 


\section{Research Article}

Table 2. Cross-tabulation of study population $(n=2898)$ according to HCV test result and self-reported ever-tested and HCV status, with corresponding summary EQ-5D values.

\begin{tabular}{|c|c|c|c|c|c|c|}
\hline \multirow[t]{2}{*}{ Anonymous HCV test result } & \multicolumn{6}{|c|}{ Self-reported HCV status } \\
\hline & $\begin{array}{l}\text { Have } \\
\text { Hepatitis C }\end{array}$ & $\begin{array}{l}\text { Cleared } \\
\text { Hepatitis C }\end{array}$ & $\begin{array}{l}\text { Don't have } \\
\text { Hepatitis C }\end{array}$ & Other & Never tested & All \\
\hline \multicolumn{7}{|l|}{ Antibody $^{+} / \mathrm{RNA}^{+}$} \\
\hline $\mathrm{N}$ & 584 & 49 & 193 & 87 & 179 & 1092 \\
\hline Median index EQ-5D & 0.66 & 0.73 & 0.74 & 0.74 & 0.73 & 0.69 \\
\hline \multicolumn{7}{|l|}{$\mathrm{RNA}^{-}$} \\
\hline $\mathrm{N}$ & 162 & 241 & 829 & 116 & 458 & 1806 \\
\hline Median index EQ-5D & 0.63 & 0.73 & 0.76 & 0.74 & 0.78 & 0.73 \\
\hline
\end{tabular}

'Other' includes the responses 'Awaiting result', 'Did not get result', 'Don't know', and missing data.

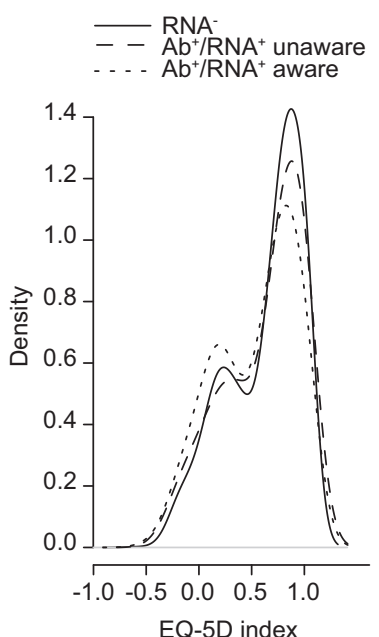

Fig. 2. Smoothed density plot of unadjusted EQ-5D quality of life measurements according to chronic $\mathrm{HCV}$ infection/awareness status.

unaware groups. Age, a high level of alcohol consumption (above 21 units/week for males, above 14 units/week for females), being an active injector, ever being on methadone treatment, ever being homeless, and residing in GGC were significantly negatively associated with the EQ-5D index, and male sex was significantly positively associated with QoL (Table 3). No two-way interaction terms met the criterion for inclusion.

Exclusion of those RNA-positive respondents who had reported either 'Don't have hep C' or 'Cleared hep C' from the regression analysis did not appreciably change the pattern of results; the adjusted regression coefficient for chronic $\mathrm{HCV} /$ aware was $-0.08(p=0.006)$ and for not chronically infected was -0.03 $(p=0.138)$. Exclusion of those RNA-negative respondents who reported that they 'Have hep C' $(12 \%, 162 / 1348)$ from analysis also did not change results; the adjusted regression coefficient for chronic HCV/aware was $-0.09(p=0.003)$ and for not chronically infected was $-0.03(p=0.177)$. A supplementary analysis conducted for the subgroup of recent injectors (i.e., reporting having injected within the previous 4 weeks, $n=1937$ ) indicated little difference in the association between HCV status and EQ-5D compared with the entire cohort: the adjusted regression coefficient for chronic HCV/aware was $-0.13(p=0.002)$ and for not chronically infected was $-0.06(p=0.08)$.

\section{Discussion}

This is the first study to compare health-related QoL in PWID who are chronically infected with HCV and aware, with those who are chronically infected but unaware of their infected status, and those who are not chronically infected. We found that those chronically infected PWID that were aware of their serostatus (relating to those who had been diagnosed) had a significantly lower EQ-5D summary index than those who were chronically infected but unaware of their serostatus. Thus, diagnosis with HCV appears to have had an additional diminishing effect upon QoL, beyond any potential reduction in QoL associated with infection itself. Female sex, older age, heavy alcohol consumption, active injecting, current treatment with methadone, and ever being homeless were all independently associated with reduced QoL. Residing in GGC compared with other health board areas was associated with the largest QoL reduction, which captures the greater relative social deprivation in this region [20]. Restricting analysis to recent PWID only (i.e., those who reported injecting within the previous 4 weeks) made no difference to the pattern of either outcome measure. Importantly, adjustment for current age, which is itself highly correlated with length of injecting career, is a proxy for the duration of chronic infection.

The effect on QoL from receiving a positive diagnosis needs to be considered when calculating the CE of HCV testing/screening programmes. Current CE models assume that $\mathrm{QoL}$ is reduced with chronic infection [10,21]. Even amongst HCV antibody-positive patients with no history of IDU, diagnosis has been shown to reduce QoL [6]. In addition, treatment is not initiated on all RNA-positives; not being selected for management and antiviral therapy can reduce QoL [22]. Although approaches have been developed to successfully test and diagnose PWID [23], attendance at specialist clinics and rates of treatment initiation among PWID are an issue.

For the population of PWID attending injecting equipment provision services across Scotland, QoL was poorer than UK population norms, which corroborates the results of previous studies $[4,6,24]$. Based on a cross-sectional study of 833 patients in the Swiss Hepatitis C Cohort Study, Helbling et al. argue that this reduction may be due to other differences with the reference population rather than HCV per se [25]. However, in a systematic review of studies comparing QoL (using the SF-36 instrument) in HCV patients to matched controls, Spiegel et al. reported QoL to be consistently and clinically significantly lower in patients who were HCV antibody-positive, and that the impact of HCV 
Table 3. Results of multifactorial quantile regression analysis, where the outcome is EQ-5D index value. Analysis additionally excluded individuals with missing data on any of: ever on methadone $(n=0)$, ever homeless $(n=4)$, ever imprisoned $(n=4)$; leaving 2894 cases for analysis.

\begin{tabular}{|c|c|c|c|c|c|c|c|}
\hline Covariate & Level & Median (IQR) & $\begin{array}{l}\text { Unadjusted } \\
\text { coefficient }\end{array}$ & $p$ value & $\begin{array}{l}\text { Adjusted } \\
\text { coefficient }\end{array}$ & SE & $p$ value \\
\hline Intercept & & & & & 1.21 & 0.052 & $<0.001$ \\
\hline \multirow[t]{3}{*}{ HCV status } & $\mathrm{RNA}^{-}$ & $0.73(0.35-0.85)$ & 0.00 & 1.0 & -0.03 & 0.022 & 0.134 \\
\hline & $\mathrm{Ab}^{+} / \mathrm{RNA}^{+} /$unaware & $0.73(0.31-1.00)$ & - & - & & - & \\
\hline & $\mathrm{Ab}^{+} / \mathrm{RNA}^{+} / \mathrm{aware}$ & $0.66(0.21-0.85)$ & -0.07 & 0.018 & -0.09 & 0.030 & 0.005 \\
\hline \multirow[t]{2}{*}{ Sex } & Female & $0.69(0.29-0.85)$ & - & - & & - & \\
\hline & Male & $0.73(0.29-0.85)$ & 0.04 & 0.066 & 0.07 & 0.020 & $<0.001$ \\
\hline \multicolumn{2}{|c|}{ Age (linear, per decade) } & & -0.09 & $<0.001$ & -0.08 & 0.012 & $<0.001$ \\
\hline \multirow[t]{3}{*}{ Alcohol use } & Non-drinker & $0.73(0.29-0.85)$ & - & - & - & - & - \\
\hline & Moderate & $0.80(0.41-1.00)$ & 0.07 & 0.001 & 0.03 & 0.015 & 0.098 \\
\hline & High & $0.66(0.21-0.85)$ & -0.07 & 0.030 & -0.07 & 0.030 & 0.012 \\
\hline \multirow[t]{3}{*}{ Injecting frequency } & Non-active injector & $0.73(0.29-0.85)$ & - & - & - & - & - \\
\hline & $<1 / d$ & $0.73(0.29-0.85)$ & 0.00 & 1.0 & -0.06 & 0.018 & 0.001 \\
\hline & $\geq 1 / d$ & $0.73(0.29-0.85)$ & 0.00 & 1.0 & -0.08 & 0.020 & $<0.001$ \\
\hline \multirow[t]{3}{*}{ Ever on methadone } & No & $0.85(0.41-1.00)$ & - & - & - & - & - \\
\hline & Currently & $0.73(0.27-0.85)$ & -0.12 & $<0.001$ & -0.08 & 0.026 & 0.003 \\
\hline & In past & $0.73(0.38-0.85)$ & -0.12 & $<0.001$ & -0.05 & 0.026 & 0.080 \\
\hline \multirow[t]{3}{*}{ Ever homeless } & No & $0.80(0.41-1.00)$ & - & - & - & - & - \\
\hline & Yes, >6 mo ago & $0.73(0.29-0.85)$ & -0.07 & $<0.001$ & -0.07 & 0.015 & $<0.001$ \\
\hline & Yes, in last 6 mo & $0.66(0.26-0.85)$ & -0.14 & $<0.001$ & -0.12 & 0.029 & $<0.001$ \\
\hline \multirow[t]{2}{*}{ Ever imprisoned } & No & $0.74(0.38-0.88)$ & - & - & - & - & - \\
\hline & Yes & $0.71(0.26-0.85)$ & -0.04 & 0.088 & -0.02 & 0.015 & 0.248 \\
\hline \multirow{2}{*}{$\begin{array}{l}\text { Health Board } \\
\text { of residence }\end{array}$} & Other & $0.76(0.41-0.88)$ & - & - & - & - & - \\
\hline & GGC & $0.66(0.22-0.85)$ & -0.10 & $<0.001$ & -0.08 & 0.018 & $<0.001$ \\
\hline
\end{tabular}

GGC, Greater Glasgow \& Clyde. Self-rated alcohol use categories were defined as: high ( $>21$ units/week for men; $>14$ for women); moderate ( $>0$ to 21 units/week for men; $>0$ to 14 for women); and non-drinker (0 units/week).

infection was most pronounced on the vitality, general health, physical function, and social function subscales of SF-36 [5].

Our principle finding was a reduction in QoL between HCVinfected PWID who were aware of their infected status compared with those who were unaware of their status. Reduced QoL in aware compared with unaware chronically HCV-infected individuals may be an effect of labelling and/or of receiving a positive diagnosis. Awareness of (or belief about) positive HCV status in infected individuals was associated with lower QoL in two previous studies [4,7]. In the first, HCV-infected PWID who were $(n=15)$ and were not $(n=17)$ aware of their serostatus were compared in a retrospective Australian study; using the SF-36 questionnaire, the authors found that 'aware' PWID had a lower QoL, 26 years after being infected [7]. In the second study, the authors compared QoL (via SF-36) in uninfected $(n=97)$ and chronically HCV-infected $(\mathrm{n}=102)$ PWID in Oslo, Norway, and found no difference between the two groups [4]. However, in the HCV-positive group those PWID that were aware of their infected status scored lower in 4 of 8 dimensions compared with those who were unaware. Compared with the previous studies reviewed above, our study population is much larger and involved PWID recruited in community-based settings in pharmacies and harm reductions services across Scotland.

We observed no evidence for a difference in QoL between PWID who were not chronically infected and chronic HCV/unaware PWID after adjusting for important covariate differences. This key result of our study, which had more statistical power than most previous studies, is consistent with findings of no difference in overall QoL between HCV-infected and uninfected groups [25-27]. For instance, comparing patients with and without viraemia, Helbling et al. found that QoL did not differ between $A b+v e, R N+v e(n=555)$ and Ab+ve, RNA-ve $(n=262) H C V$ infected persons [25]. In a USA study of 619 PWID, $51 \%$ of whom were $\mathrm{HCV}$ antibody-positive, Costenbader et al. found that HCV infection was associated with a significantly reduced QoL on only 3 of the 8 SF-36 subscales [28]. Such comparisons should be made cautiously, however, as PWID populations differ from clinical populations in a number of respects, such as the presence of co-morbidities and the time since infection. In the absence of developing liver disease, HCV infection may not be sufficient to affect QoL. Given that the injecting career length of our study population was on average only 10 years (corresponding to a maximum of 10 years of disease progression), and in the context that chronic HCV infection can take decades to progress to complications (5-15\% develop cirrhosis after 20 years of infection [29]), it is perhaps unsurprising that our adjusted analysis found no difference in QoL between chronic HCV/unaware and not chronically infected PWID. Further research on QoL in those with longer injecting careers is required.

Our results must be interpreted in the context of several potential limitations regarding the recruitment of the study population and in the determination/quantification of QoL. First, we have assumed that willingness to participate in all aspects of the NESI survey did not differ across HCV status groups. However, if QoL differences between respondents and non-respondents were not distributed equally across the three HCV status groups, then our results may not be representative of the PWID population as a whole. 


\section{Research Article}

Second, our study population predominantly consists of current injectors, and thus is clearly relevant for CE studies specifically addressing this group [30]. However, ex-PWID are under-represented (they were only recruited if accessing harm reduction services) and so sampling bias and generalisability to ex-PWID needs to be considered.

Third, our study population consisted of PWID with a relatively short injecting career (median 10 years); therefore (as outlined above) we do not expect many to have developed HCV-related complications within this relatively short duration of living with chronic infection. However, those PWID who have developed HCV-related disease are more likely to have been tested and diagnosed (and so will be in the chronic HCV/aware group); the difference in QoL we observed between chronic $\mathrm{HCV} /$ aware and chronic $\mathrm{HCV} /$ unaware individuals needs to be considered in light of this potential bias. Having said this, among HCV antibody- and RNA-positive PWID who had been tested in the past, QoL was still lower among those aware (0.66; Table 2$)$ compared with those unaware (0.74) of their infection.

Fourth, due to lack of data on social deprivation, we were unable to control for socio-economic inequalities between HCV status groups. Partial control was achieved by adjusting for health board, a greater number of chronic HCV/aware and chronic $\mathrm{HCV} /$ unaware respondents resided in GGC HB, which revealed large independent effects for this covariate. Adjustment for socio-economic variables may influence the QoL difference seen between chronic HCV/aware and chronic HCV/unaware groups. Finally, because of our cross-sectional study design, we cannot make causal inferences regarding the relationship between awareness of serostatus and QoL. More research is required, ideally comparing QoL elicited before and after diagnosis with HCV, to clarify this issue.

For PWID chronically infected with HCV, being aware of their infected status was associated with a reduced health-related QoL; there was no evidence for any QoL reduction solely attributable to the presence of infection in undiagnosed PWID, when age (a proxy for duration of infection) and other covariates are controlled for. These findings provide useful data on the change in QoL post-diagnosis. Additional research is required to ascertain the relative contributions of the duration of HCV infection (particularly in infected ex-PWID, who will have been infected for a longer time) and awareness of one's infected status to QoL.

On the basis of the maxim that an intervention should do more good than harm, our finding that awareness of infection status among chronically HCV-infected current PWID is associated with a reduction in QoL implies that unless clinicians are prepared, and have the means, to act on a HCV diagnosis, the case for promoting the identification of infected individuals is weak.

\section{Conflict of interest}

The authors who have taken part in this study declared that they do not have anything to disclose regarding funding or conflict of interest with respect to this manuscript.

\section{References}

[1] Hutchinson S, Roy K, Wadd S, Bird S, Taylor A, Anderson E. Hepatitis C virus infection in Scotland: epidemiological review and public health challenges. Scott Med J 2006;51:8-15.
[2] McDonald SA, Donaghy M, Goldberg DJ, Hutchinson S, Robertson C, Bird S, et al. A population-based record linkage study of mortality in hepatitis Cdiagnosed persons with or without HIV coinfection in Scotland. Stat Methods Med Res 2009;18:271-283.

[3] McDonald SA, Hutchinson SJ, Mills PR, Bird SM, Cameron S, Dillon JF, et al. The influence of hepatitis $C$ and alcohol on liver-related morbidity and mortality in Glasgow's injecting drug user population. J Viral Hepat 2011;18:e126-33.

[4] Dalgard O, Egeland A, Skaug K, Vilimas K, Steen T. Health-related quality of life in active injecting drug users with and without chronic hepatitis $C$ virus infection. Hepatology 2004;39:74-80.

[5] Spiegel BM, Younossi ZM, Hays RD, Revicki D, Robbins S, Kanwal F. Impact of hepatitis $C$ on health related quality of life: a systematic review and quantitative assessment. Hepatology 2005;41:790-800.

[6] Foster GR, Goldin RD, Thomas HC. Chronic hepatitis C virus infection causes a significant reduction in quality of life in the absence of cirrhosis. Hepatology 1998;27:209-212.

[7] Rodger AJ, Jolley D, Thompson SC, Lanigan A, Crofts N. The impact of diagnosis of hepatitis C virus on quality of life. Hepatology 1999;30: 1299-1301.

[8] Grieve R, Roberts J, Wright M, Sweeting M, DeAngelis D, Rosenberg W, et al. Cost effectiveness of interferon alpha or peginterferon alpha with ribavirin for histologically mild chronic hepatitis C. Gut 2006;55:1332-1338.

[9] Grishchenko M, Grieve RD, Sweeting MJ, De Angelis D, Thomson BJ, Ryder SD, et al. Cost-effectiveness of pegylated interferon and ribavirin for patients with chronic hepatitis $C$ treated in routine clinical practice. Int J Technol Assess Health Care 2009;25:171-180.

[10] Thompson Coon J, Castelnuovo E, Pitt M, Cramp M, Siebert U, Stein K. Case finding for hepatitis $C$ in primary care: a cost utility analysis. Fam Pract 2006;23:393-406

[11] University of the West of Scotland, Health Protection Scotland and West of Scotland Specialist Virology Centre. The needle exchange surveillance initiative: prevalence of HCV, HIV and injecting risk behaviours among injecting drug users attending needle exchanges in Scotland, 2008/2009; 2010.

[12] Information Services Division (ISD). Injecting equipment provision in Scotland survey 2009/2010. Edinburgh: ISD; 2011.

[13] Brooks R. EuroQol: the current state of play. Health Policy 1996;37:53-72.

[14] The EuroQol Group. EuroQol - a new facility for the measurement of healthrelated quality of life. Health Policy 1990;16:199-208.

[15] Nosyk B, Guh DP, Sun H, Oviedo-Joekes E, Brissette S, Marsh DC, et al. Health related quality of life trajectories of patients in opioid substitution treatment. Drug Alcohol Depend 2011;118:259-264.

[16] MVH Group. The measurement and valuation of health. Final report on the modelling of valuation tariffs. York: MVH Group, Centre for Health Economics; 1995.

[17] Judd A, Parry J, Hickman M, McDonald T, Jordan L, Lewis K, et al. Evaluation of a modified commercial assay in detecting antibody to hepatitis $\mathrm{C}$ virus in oral fluids and dried blood spots. J Med Virol 2003;71:49-55.

[18] Kind P, Hardman G, Macran S. UK population norms for EQ-5D. York: University of York, Centre for Health Economics; 1999.

[19] R Development Core Team. R: a language and environment for statistical computing. Vienna: R Foundation for Statistical Computing; 2008.

[20] Hanlon P, Lawder RS, Buchanan D, Redpath A, Walsh D, Wood R, et al. Why is mortality higher in Scotland than in England and Wales? Decreasing influence of socioeconomic deprivation between 1981 and 2001 supports the existence of a 'Scottish effect'. J Public Health 2005;27:199-204.

[21] Castelnuovo E, Thompson-Coon J, Pitt M, Cramp M, Siebert U, Price A, et al. The cost-effectiveness of testing for hepatitis $C$ in former injecting drug users. Health Technol Assess 2006:10:1-93.

[22] Fontana RJ, Bieliauskas LA, Lindsay KL, Back-Madruga C, Wright EC, Snow KK, et al. Cognitive function does not worsen during pegylated interferon and ribavirin retreatment of chronic hepatitis C. Hepatology 2007;45: 1154-1163.

[23] Cullen BL, Hutchinson SJ, Cameron SO, Anderson E, Ahmed S, Spence E, et al. Identifying former injecting drug users infected with hepatitis $\mathrm{C}$ : an evaluation of a general practice-based case-finding intervention. J Public Health (Oxf) 2012;34:14-23.

[24] Bonkovsky HL, Woolley JM. Reduction of health-related quality of life in chronic hepatitis $C$ and improvement with interferon therapy: the consensus interferon study group. Hepatology 1999;29:264-270.

[25] Helbling B, Overbeck K, Gonvers JJ, Malinverni R, Dufour JF, Borovicka J, et al. Host- rather than virus-related factors reduce health-related quality of life in hepatitis C virus infection. Gut 2008;57:1597-1603. 


\section{JOURNAL OF HEPATOLOGY}

[26] Dalgard O. Follow-up studies of treatment for hepatitis $C$ virus infection among injection drug users. Clin Infect Dis 2005;40:S336-8.

[27] Thein HH, Butler T, Krahn M, Rawlinson W, Levy MH, Kaldor JM, et al. The effect of hepatitis $C$ virus infection on health-related quality of life in prisoners. J Urban Health 2006;83:275-288.

[28] Costenbader EC, Zule WA, Coomes CM. The impact of illicit drug use and harmful drinking on quality of life among injection drug users at high risk for hepatitis C infection. Drug Alcohol Depend 2007;89:251-258.
[29] Thein HH, Yi Q Dore GJ, Krahn MD. Estimation of stage-specific fibrosis progression rates in chronic hepatitis $C$ virus infection: a meta-analysis and meta-regression. Hepatology 2008;48:418-431.

[30] Martin NK, Vickerman P, Miners A, Foster GR, Hutchinson SJ, Goldberg DJ, et al. The cost-effectiveness of HCV antiviral treatment for injecting drug user populations. Hepatology 2011;55:49-57. 